\title{
Endoscopic transnasal management of inverted papilloma involving frontal sinuses
}

\author{
Tomasz Gotlib ${ }^{1}$, Antoni Krzeski², Marta Held-Ziółkowska' ${ }^{1}$, Kazimierz Niemczyk ${ }^{1}$ \\ 1Department of Otolaryngology, Medical University of Warsaw, Poland \\ 2Department of Otolaryngology Dentistry Division, Medical University of Warsaw, Poland
}

Videosurgery Miniinv 2012; 7 (4): 299-303

DOI: $10.5114 /$ wiitm.2011.30827

\begin{abstract}
Inverted papilloma is a benign locally aggressive tumor of paranasal sinuses which has been traditionally managed with external surgical approaches. Advances in tumor imaging, surgical instrumentation and intraoperative visualization have led to a gradual shift to endonasal attachment-oriented surgery. Involvement of both frontal sinuses by inverted papilloma is rare. There are scant reports in the literature regarding this topic. We present 2 cases of the tumor involving both frontal sinuses removed by median drainage (Draf III procedure) under endoscopic guidance without any additional external approach. The whole cavity of both frontal sinuses was easily inspected at the end of the procedure. No early or late complications were observed. No recurrence was seen in 1-year or 2-year follow-up. Management of frontal sinus inverted papilloma with the endoscopic median drainage approach is feasible and seems to be effective.
\end{abstract}

Key words: frontal sinus, inverted papilloma, endoscopic modified Lothrop, Draf III.

\section{Introduction}

Inverted papilloma (IP) is a benign locally aggressive tumor of paranasal sinuses. The incidence of its malignant transformation is estimated at $1 \%$ to $5 \%$ [1]. The most common site of tumor origin is the lateral wall of the nasal cavity [2]. Incomplete removal of the attachment site is known to be the reason for recurrence of the tumor.

Traditionally these lesions have been treated via external approaches such as Denker or medial maxillectomy performed from a lateral rhinotomy approach. The recurrence rate ranges between 0 and $60 \%$ depending on the approach used [2-4].

Endoscopic removal of benign tumors of paranasal sinuses has become popular in the last 15 years [5-8]. Advances in tumor imaging, surgical instrumen- tation and intraoperative visualization have led to a gradual shift to endonasal attachment-oriented surgery. Efficacy of the endoscopic approach in inverted papilloma surgery was supported by a systemic review of the literature showing a low recurrence rate and low morbidity of this type of treatment [8]. However, endoscopic treatment of frontal sinus IP is still challenging because of the narrow, angulated, anatomically variable frontal recess and its proximity to the olfactory fossa. Involvement of the frontal sinus is rare and varies from $1.6 \%$ to $15 \%$ of cases of IP $[9,10]$.

Frontal sinus IP has been managed with external surgical approaches such as the Lynch or osteoplastic flap procedure (OPF). These methods however are associated with postoperative complications such as scar formation or hypoesthesia. With the use of clas- 
sical FESS instrumentation it is possible to remove most IP with the attachment in the frontal recess, but rarely those originating from the sinus wall because of inadequate exposure [11].

The introduction of irrigated angulated burrs facilitated extended frontal sinus approaches such as Draf IIb and Draf III (median drainage). The Draf III procedure, also known as the modified endoscopic Lothrop procedure, enables visualization of the whole cavity of both frontal sinuses, which makes removal of the lesion originating from the frontal sinus feasible in most cases [4, 12]. There are limited reports presenting series of patients with frontal sinus IP treated endoscopically in the literature and only a few describing bilateral frontal sinus IP.

We present 2 patients with the tumor involving both frontal sinuses both treated with the Draf III approach (median drainage). The aim of this study is to present our experience in management of this type of tumor.

\section{Case reports}

\section{Case report 1}

A 67-year-old patient presented with symptoms of chronic rhinosinusitis without any history of previous sinus surgery. Rhinoscopy revealed a polypoid grey mass in both nasal passages. Sinus computed tomography (CT) showed total opacification of the anterior and posterior ethmoids, frontal sinus and nasal cavity on the right side, and anterior ethmoids and frontal sinus on the left side as well as lack of a frontal intersinus septum, and presence of a lowdensity bony-like structure in the midline (Figure $1 \mathrm{~A}$ ). The tumor was removed under general anesthesia

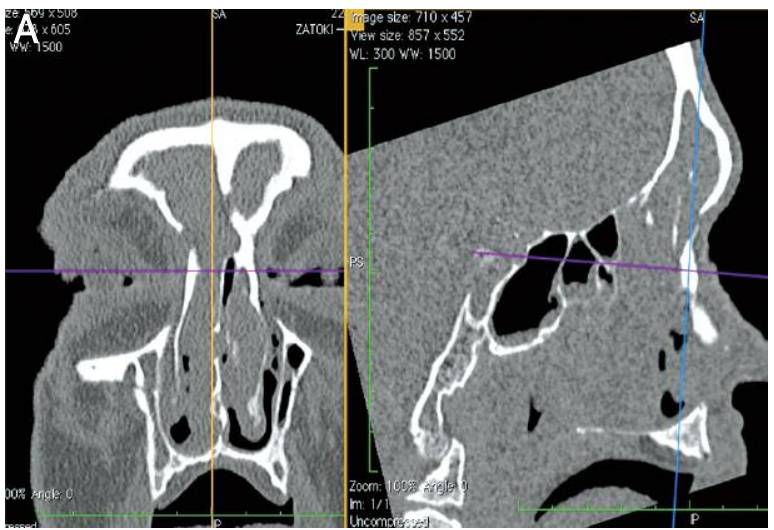

Figure 1. Computed tomography of patient 1 before (A) and after (B) the surgery

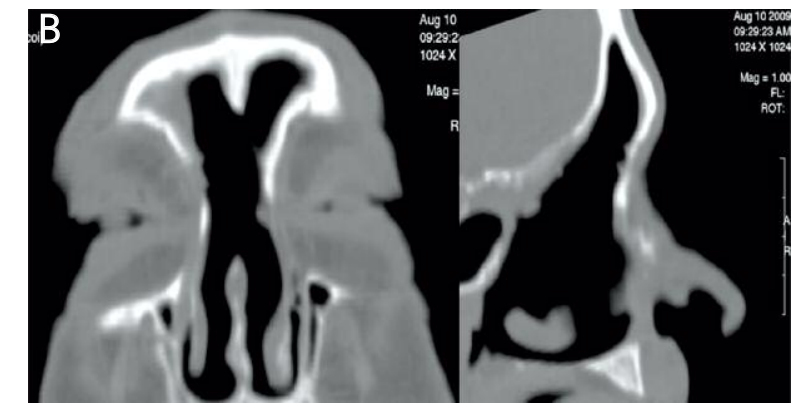

using a $30^{\circ}$ scope, shaver and curved diamond drill. After the lesion was debulked and removed from the nasal cavity and anterior ethmoids, bilateral fullhouse ethmoidectomy was performed. In the superior-anterior portion of the nasal septum the perforation filled with the mass of the tumor was visualized. No attachment to the edges of this perforation was seen. At this stage of the procedure it became clear that the site of origin of the lesion was located inside the right frontal sinus. The remaining part of the upper nasal septum was removed and the median drainage procedure was completed. Bony fragments found inside the sinus were probably frontal cell and intersinus septum remnants. The tumor origin was found on the lateral posterior wall of the sinus. The underlying bone was drilled down. The whole cavity of both frontal sinuses was easily inspected with the $30^{\circ}$ and $45^{\circ}$ scope at the end of the procedure. Histopathology revealed inverted papilloma. One year postoperatively endoscopic examination revealed thickening of the mucous membrane of the sinus with no signs of recurrence although CT showed opacification of the lateral aspect of the right frontal sinus (Figure $1 \mathrm{~B}$ ). Two years postoperatively the patient was diagnosed with advanced-stage oesophageal cancer. Palliative treatment was started and rhinological follow-up was closed.

\section{Case report 2}

A 55-year-old man with a history of recurrent inverted papilloma presented with signs of relapse of the tumor. He had previously undergone multiple polypectomies. After IP was finally diagnosed the patient was treated with right medial maxillectomy via the sublabial approach. He was reoperated 


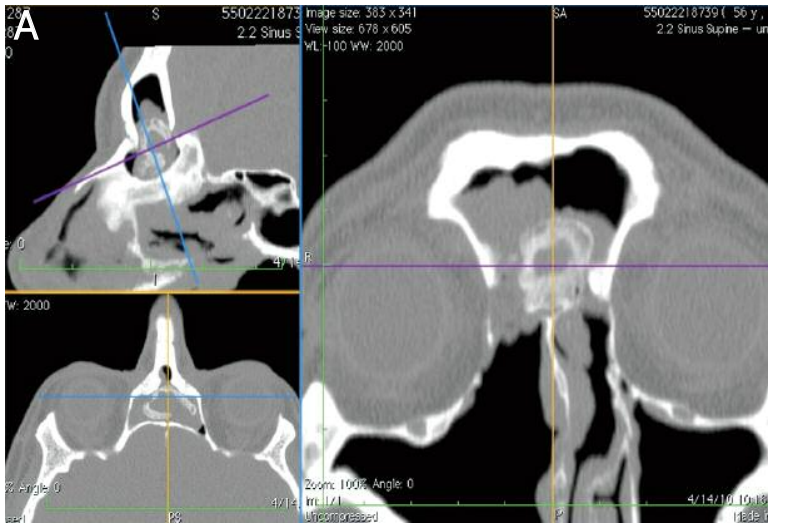

Figure 2. Computed tomography of patient 2 before (A) and after (B) the surgery

under endoscopic guidance 2 years later because of recurrence. At that time the frontal sinus as seen on CT was opacified but during the procedure no wide exposure approach to the sinus was utilized. Four years after this reoperation endoscopy showed a pinkish cauliflower-like mass bleeding on touch under the remnants of the right middle turbinate. A biopsy confirmed recurrence of IP.

The CT showed no signs of tumor in the right maxillary sinus, partial opacification of both frontal sinuses, lack of intersinus septum, presence of a lowdensity oval-shaped bony-like structure attached to the skull base at the level of the right anterior ethmoidal artery and marked thickening of the bone in the right olfactory groove with adjacent opacified ethmoid cell (Figure $2 \mathrm{~A}$ ). Magnetic resonance imaging (MRI) showed mucus retention in the upper part of both frontal sinuses.

The Median drainage (Draf III) procedure was performed under general anesthesia using a $30^{\circ}$ rigid scope. After perforation of the upper part of the nasal septum the frontal sinus was entered in the midline and the bony bridges covering the right and left frontal recess were drilled down with a $0.5 \mathrm{~mm}$ diamond burr. The tumor was mobile, elastic, not adherent to the mucosa of the upper part of sinuses mucosa. After exposure it was removed in two pieces. Attachment of the lesion was localized in the right supraorbital recess. Despite widening of the access by opening the ethmoid cell adjacent to the olfactory groove, it was still not possible to insert a shaver or drill into the narrowest part of the supraorbital recess. After removal of the tumor the site of attachment, whose diameter was about $1.0 \mathrm{~cm}$, was coagulated with a diode laser at a power setting of $10 \mathrm{~W}$.

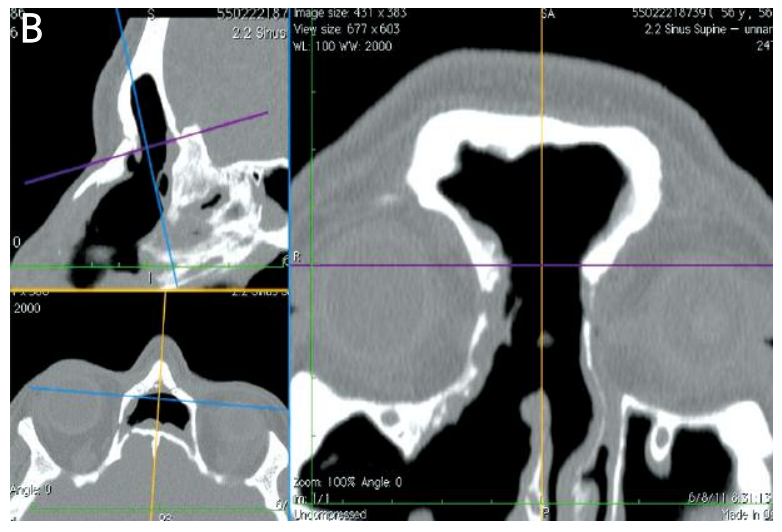

At the end of the procedure the dimension of the created ostium was about $1.5 \mathrm{~cm}$ and $2 \mathrm{~cm}$ in vertical and axial planes respectively. This enabled inspection of both frontal sinuses including the anterior table and both supraorbital recesses with the $45^{\circ}$ scope.

Endoscopic examination and CT performed one year after the procedure revealed no signs of relapse of the tumor (Figure $2 \mathrm{~B}$ ).

\section{Discussion}

Traditionally IP of the frontal sinus has been managed with OPF. Obliteration of the sinus with fat is contraindicated because it makes radiological control difficult. For this reason the "above and below" approach enabling sinus drainage and endoscopic inspection in the postoperative period was found to be a more appropriate mode of treatment [11]. Dubin and Johnson presented a series of 5 patients initially treated endoscopically using classical FESS instrumentation. All of these patients underwent a second stage procedure which was an external approach in all cases except for one. The authors did not use extended frontal sinus procedures such as Draf Ilb or Draf III although in their opinion they could be effective [11].

Due to complex anatomy, high risk of complications and recurrence, a purely endoscopic approach has not been used routinely in cases of frontal sinus involvement.

During the last decade several authors have presented a limited number (1 to 2 ) of patients with frontal sinus or recess IP treated endoscopically $[8,13$, 14]. A series of 8 patients was presented in 2008 by Zhang. There were 4 patients with frontal recess 
involvement, treated with the Draf lla procedure; three patients with unilateral involvement of the frontal sinus, treated with Draf IIb; and 2 patients with involvement of both frontal sinuses, both treated with the Draf III procedure. All of the tumors were unifocal (had a single attachment site). There were 3 patients with a history of previous surgery. No additional external approach was used (frontal trephination). There were no complications and all the patients remained disease free (observation period ranged from 5 months to 34 months).

One year later Yoon et al. presented a series of 18 patients with frontal sinus inverted papilloma [15]. Twelve of these subjects underwent surgical management in the past. During the study period 2 of the subjects were treated primarily with OPF, and 16 endoscopically. Five out of these required additional endoscopic frontal trephination during the surgery. Multifocal tumor attachment was found in 6 cases. Endoscopic modified Lothrop procedure (EML, equivalent to Draf III) was used in 6 cases. In the EML treated subgroup multifocal tumor was present in 4 out of 6 patients. In 2 cases surgery was complicated with a cerebrospinal fluid leak. Recurrence was observed in 4 subjects. These patients were successfully treated with endonasal procedures.

It is well recognized that most recurrences of IP result from incomplete removal of the attachment site, especially its bony component [2]. Radiological studies showed that in more than $90 \%$ of cases it is possible to identify the site of attachment of IP by the presence of focal bony thickening in high-resolution CT [16]. Magnetic resonance imaging is useful to distinguish the border between mucus retention (hyperintense in T2 images) and the tumor. Preoperative planning based on high-resolution $\mathrm{CT}$ and MRI enables an endoscopic, tailored, attachment-oriented approach [10]. If the lesion is limited to the frontal recess and opacification of the frontal sinus is due to mucus retention, Draf Ila or IIb is the most convenient approach. However, if the origin of the tumor is located within the sinus or there is involvement of the contralateral side, probably the median drainage (Draf III) will be the most appropriate technique.

This procedure seems to be the most appropriate for endoscopic treatment of bilateral and/or multifocal frontal sinus lesions. Although intranasal surgery can be effective in most cases, some anatomical variants such as small antero-posterior dimension of the frontal recess can make it impossible $[17,18]$. Feasibility of intranasal radical removal of the frontal sinus
IP can be adequately assessed intraoperatively. In case of multifocal tumor or complications OPF may be needed. For this reason all of the patients should be informed about the potential necessity of OPF use and should give informed consent for this procedure.

In case 2 of our study during planning of the procedure we expected multifocal involvement due to multiple previous procedures. To our surprise, favorably for the patient, there was a single site of attachment. Moreover, it was located in the vicinity of the hyperostotic focus in the right supraorbital recess and olfactory fossa as suggested by CT. To gain control over the part of the tumor hidden in the supraorbital recess we used a diode laser which was easy to manipulate within the sinus. Zhang et al. reported use of bipolar cautery in the site of tumor attachment. In both studies this thermal ablation was effective although the number of patients is too small to draw any definite conclusions [10].

In both of our cases the lesion was bilateral although the site of origin was unilateral. This is concordant with the findings of Zhang, who observed the same phenomenon in their two cases of bilateral frontal IP.

In conclusion, bilateral frontal sinus inverted papilloma can be effectively treated with the median drainage procedure.

\section{References}

1. Myers EN, Fernau JL, Johnson JT, et al. Management of inverted papilloma. Laryngoscope 1990; 100: 481-90.

2. Krouse JH. Endoscopic treatment of inverted papilloma: safety and efficacy. Am J Otolaryngol 2001; 22: 87-99.

3. Lawson W, Ho BT, Shaari CM, Biller HF. Inverted papilloma: a report of 112 cases. Laryngoscope 1995; 105: 282-8.

4. Lund VJ, Stammberger H, Nicolai $P$, et al. European position paper on endoscopic management of tumors of the nose, paranasal sinuses and skull base. Rhinology Suppl 2010; 22: $1-143$

5. Szyfter W, Popko M, Leszczyńska M, Gawęcki W. Exclusively endoscopic approach for juvenile angiofibroma in an adult a case report. Videosurgery Miniinv 2010; 5: 107-9.

6. Szyfter W, Popko M, Borucki Ł. Outcomes of endoscopic surgery, endoscopic-assisted surgery and open surgery in the treatment of juvenile nasopharyngeal angiofibroma. Videosurgery Miniinv 2009; 4: 138-46.

7. El Sharkavwy AA, Elmorsy SM. Transnasal endoscopic treatment of recurrent juvenile nasopharyngeal angiofibroma. Int J Pediatr Otorhinolarynolaryngol 2011; 75: 620-3.

8. Busquets JM, Hwang PH. Endoscopic resection of sinonasal inverted papilloma: a meta-analysis. Otolaryngol Hesd Neck Surg 2006; 134: 476-82. 
9. Shohet JA, Duncavage JA. Managenent of the frontal sinus with inverted papilloma. Otolaryngol Head Neck Surg 1996; 114: 649-52.

10. Zhang L, Han D, Wang C, et al. Endoscopic management of the inverted papilloma with the attachment to the frontal sinus drainage pathway. Acta Oto-Laryngol 2008; 128: 561-8.

11. Dubin MG, Sonnenburg RE, Melroy CT, et al. Staged endoscopic and combined open/endoscopic approach in the management of inverted papilloma of the frontal sinus. Am J Rhinol 2005; 19: 442-5.

12. Becker SS, Bomeli SR, Gross CW, Han JK. Limits of endoscopic visualization and instrumentation in the frontal sinus. Otolaryngol Head Neck Surg 2006; 135: 917-21.

13. Wormald PJ, Ooi E, van Hasselt CA, Nair S. Endoscopic removal of sinonasal inverted papilloma including endoscopic medial maxillectomy. Laryngoscope 2003; 113: 867-73.

14. Jameson MJ, Kountakis SE. Endoscopic management of extensive inverted papilloma. Am J Rhinol 2005; 19: 446-51.

15. Yoon B, Batra PS, Citardi MJ, Roh H. Frontal sinus inverted papilloma: surgical strategy based on the site of attachment. Am J Rhinol 2009; 23: 337-41.

16. Lee DK, Chung SK, Dhong HJ, et al. Focal hyperostosis on CT of sinonasal inverted papilloma as a predictor of tumor origin. Am J Neuroradiol 2007; 28: 618-21.

17. Cassiano RR, Livingston JA. Endoscopic Lothrop procedure: the University of Miami Experience. Am J Rhinol 1998; 12: 335-9.

18. Farhat FT, Figueroa RE, Kountakis SE. Anatomic measurements for the endoscopic modified Lothrop procedure. Am J Rhinol 2005; 19: 293-6.

Received: 3.04.2012, Revised: 28.05.2012, Accepted: 7.07.2012. 